\title{
Dagkirurgi og anestesi
}

\author{
Sammendrag \\ Bakgrunn. Flertallet av kirurgiske \\ inngrep i Norge gjøres dagkirurgisk. \\ Det er nødvendig at mange grupper \\ leger og annet helsepersonell forhol- \\ der seg til dette. I artikkelen oppsum- \\ meres viktig viten rundt håndtering av \\ dagkirurgiske pasienter.
}

\section{Materiale og metode. Artikkelen er} basert på egen forskning, klinisk erfaring fra dagkirurgisk anestesiologi og gjennomgang av litteratur fra ikke-systematiske søk i Medline og EMBASE.

Resultater. Med moderne teknikker er ikke anestesi begrensende for om en pasient kan opereres dagkirurgisk eller ikke. Når en del pasienter skal ha planlagt innleggelse etter en operasjon, skyldes det forhold knyttet til selve det kirurgiske inngrepet eller eventuelle uttalte innskrenkninger i pasientens normale helsetilstand, psykososiale status og daglige funksjonsnivå. En nyttig tilnærmingsmåte for alle behandlingsledd når man skal vurdere om dagkirurgi er mulig, er å tenke på hele behandlingsløpet. Kan denne pasienten etter dette inngrepet forventes å kunne bli sendt ut fra sykehuset på operasjonsdagen og fungere trygt hjemme eller på hotell sammen med en voksen ledsager frem til neste dag?

Fortolkning. Noen viktige forutsetninger må være på plass for å kunne avtale dagkirurgi samt foreta en sikker og god planlegging og gjennomføring. Anestesøren må ha tilgang på fullgode opplysninger om planlagt inngrep og om pasientens generelle helsetilstand, medikamentbruk, allergier og normale funksjonsnivå.

\section{Johan Ræder}

johan.rader@medisin.uio.no

Anestesiavdelingen

Oslo universitetssykehus, Ullevål

0407 Oslo

og

Institutt for sykehusmedisin

Det medisinske fakultet

Universitetet i Oslo

\section{Jørgen Nordentoft}

Anestesiavdelingen, Martina Hansens Hospital
Dagkirurgi vil si at pasienten møter opp og utskrives på dagen for et inngrep som gjøres i omfattende lokalanestesi, generell anestesi eller regionalanestesi eller krever kvalifisert postoperativ observasjon av andre årsaker. Mens bare $20-30 \%$ av alle elektive kirurgiske inngrep i Norge ble gjort dagkirurgisk tidlig i 1990-årene, er andelen i dag økt til hele $60 \%(1,2)$. Til tross for utstrakt bruk av dagkirurgi i Norge, er det til dels betydelige forskjeller mellom helseforetakene, noe som tilsier at en del steder har potensial for ytterligere økning i andel $(1,2)$.

Denne utviklingen skyldes dels fremskritt innenfor anestesiologisk og kirurgisk teknologi, men også økt bevissthet rundt effektivisering og kostnadsreduksjon innen helsevesenet. Forutsetningen for at dagkirurgi skal kunne utføres er imidlertid at pasientens sikkerhet er fullgodt ivaretatt, og at hele behandlingsløpet oppleves som kvalitetsmessig godt fra pasientens ståsted. For å oppfylle disse kriteriene, er det viktig at alle aktører innen og rundt den dagkirurgiske virksomheten er bevisst på hvilke pasienter som ikke egner seg for dagkirurgi og hvilke inngrep som ikke egner seg. Når pasient og inngrep er klarert, er det en del opplysninger om pasienten som er viktige for kirurg og anestesilege forut for inngrepet. Alle aktører bør videre kjenne til hvilke forberedelser og oppfølgingstiltak som er aktuelle utover selve sykehusoppholdet $(3,4)$.

Sikkerheten ved moderne dagkirurgi er svært høy. I et stort materiale fra Danmark var det ingen mortalitet (5). Imidlertid viser erfaringer fra Florida - hvor det forekom mange dødsfall under fettsuging - at rutiner, kompetanse og bemanning må være adekvate for å få gode resultater (6).

Anestesiteknikkene ved dagkirurgi er de samme som ved annen kirurgi: lokalanestesi, regionalanestesi, intravenøs sedasjon, generell anestesi eller ofte en kombinasjon av disse metodene, som tilpasses pasient og type inngrep. Ved dagkirurgisk anestesi er det et hovedanliggende å få pasienten raskt våken og mentalt restituert etter inngrepet (7). Videre tilstreber man å forebygge kvalme og smerte, blant annet ved å sikre best mulig smertelindring postoperativt med en multimodal kombinasjon av ikke-invasive og ikke-opioide metoder. Moderne anestesimidler går raskt ut av kroppen, men det er fremdeles viktig å være klar over at det å gjennomgå operative inngrep, generell anestesi eller omfattende regionalanestesi, er en ekstra belastning som innebærer kraftige fysiologiske forandringer.
Formålet med artikkelen er å summere opp nyere kunnskap knyttet til henvisning, forberedelser, pasientinformasjon og oppfølging av dagkirurgiske pasienter (3).

\section{Materiale og metode}

Denne artikkelen er basert på egen forskning, lang klinisk erfaring innen dagkirurgisk anestesiologi og gjennomgang av internasjonal litteratur via hjemmesider for dagkirurgiske fagmiljøer og fra ikke-systematiske litteratursøk i Medline og EMBASE.

\section{Hvilke inngrep egner seg ikke? \\ Nødvendig forbehandling}

For noen få typer inngrep er spesialisert forbehandling i sykehus over noe tid nødvendig. Dersom pasienten overnatter på sykehuset natten før inngrepet, er det per definisjon ikke dagkirurgi.

\section{Forventet tilstand postoperativt}

Egnethet for de aller fleste inngrep avhenger av hvilken tilstand pasienten forventes å være i kort tid etter inngrepet $(3,8)$. Hvis det rent medisinsk er nødvendig med fagmessig overvåking og/eller behandling utover noen timer eller samme ettermiddag/kveld, skal pasienten legges inn over natten. Dette vil være tilfelle ved de fleste øyeblikkelig hjelpoperasjoner; hvor forberedelser kan være ufullstendige, forløpet er uavklart, og man ofte vil behandle og observere pasienten etterpå. Det samme gjelder inngrep hvor pasientens helse eller tilstand er så medisinsk ustabil at man ønsker løpende oppfølging. Innleggelse vil også være nødvendig ved de fleste større inngrep i bukhule, thorax eller intrakranialt, hvor det kan foreligge stort blodtap, sterke smerter, postoperativt behov for intravenøs væske og elektrolyttbehand-

\section{Hovedbudskap}

- Dagkirurgi er svært utbredt, og informasjonsbehovet er stort for mange

- Dagkirurgi skal planlegges med fullgod sikkerhet og kvalitet

- Innleggelse skyldes ustabil helsesituasjon, generelt dårlig pasienthelse eller omfattende kirurgisk inngrep

- God pasientinformasjon og fyldige helseopplysninger ved henvisning og god oppfølging er viktig for vellykket dagkirurgi 
ling eller spesialisert stell av sår og dren. Videre vil inngrep hvor pasienten ikke kan mobiliseres, ikke er skikkelig våken eller ikke kan ta til seg flytende eller tabletter senere på samme dag, heller ikke være egnet for dagkirurgi.

\section{Utskrivningskriterier}

Allerede under planleggingen er det viktig å ha en liste over utskrivningskriterier i tankene (ramme 1) (9). Hvis man forventer at pasienten etter det aktuelle inngrepet ikke vil fylle hele listen samme ettermiddag eller kveld, så skal inngrepet ikke gjøres dagkirurgisk. Man skal også vurdere faren for alvorlige komplikasjoner som kan oppstå under hjemreise og i hjemmet; i sammenheng med inngrepets art og reiseavstand til nærmeste helseinstitusjon som kan gi adekvat hjelp. Her er det viktig å ha en «verst tenkelige hendelse» $\mathrm{i}$ tankene. Hvis det verste som kan skje er sterk smerte, kan dette behandles av en legevaktlege langt unna sykehus. Derimot vil det etter inngrep som kan gi bukhulelekkasje eller dype infeksjoner være viktig at pasienten kan rekke frem til adekvat sykehusbehandling i løpet av noen timer. Fare for alvorlig blødning (f.eks. tonsillektomi) krever enda kortere reisetid.

Muligheter for bruk av hotell eller sykehotell nær sykehuset kan muliggjøre utvidet bruk av dagkirurgi til pasienter som bor langt unna.

\section{Hvilke pasienter egner seg ikke?}

Generelt

I utgangspunktet kan alle pasienter sendes tilbake til sitt daglige miljø samme kveld, med mindre egen helse kombinert med aktuell kirurgi og anestesi gjør at deres totalsituasjon tilsier innleggelse for å ivareta sikkerhet eller kvalitet $(3,4)$. Her igjen er det viktig å se om man kan forvente at utskrivingskriteriene er oppfylt (ramme 1). Et generelt krav er at pasienten samtykker i å bli sendt hjem samme dag, føler seg trygg og er villig til å samarbeide om opplegget etter utskrivning. Videre skal pasienten organisere seg med ansvarlig ledsager til stede hos seg frem til neste dag, dette gjelder også ved utskrivning til ordinært sykehotell, som vanligvis ikke har hyppig tilsyn med beboerne. Hjemreisens lengde er ikke en avgjørende faktor i seg selv. Begrensningene er risiko for farlige komplikasjoner og om pasienten føler seg motivert for aktuell transport. Når pasienter har misbruksproblematikk og/eller ustabil psykososial situasjon bør det være lav terskel for innleggelse, igjen basert på en individuell vurdering av sikkerhet og kvalitet ved utskrivning samme dag.

\section{Sykdom}

Alle som skal henvise pasienter til kirurgisk behandling og anestesi bør kjenne til ASAklassifiseringen (10) (ramme 2). I utgangspunktet skal alle ASA I- og II-pasienter forutsettes friske nok til å gjennomgå dagkirurgi. Fedme og høy alder klassifiseres i utgangspunktet til ASA II, hvis det ikke foreligger signifikante tilleggslidelser. ASA III- og IV-pasienter bør vurderes individuelt for egnethet. Alvorlig ledsagende sykdom, psykiatrisk lidelse eller mental reduksjon er i seg selv ingen kontraindikasjon, og ASA III-pasienter i stabil tilstand kan ofte behandles dagkirurgisk $(8,11)$. Det avgjørende er om tilstanden forventes å være stabil, samt at inngrep og anestesi ikke blir for stor tilleggsbelastning.

\section{Respirasjonsproblemer}

En spesiell gruppe er pasienter med risiko for pusteproblemer etter generell anestesi, opioidbehandling eller inngrep i buk eller thorax. Dette gjelder bl.a. prematurt fødte spedbarn de første månedene etter fødsel, pasienter med uttalt søvnapnésyndrom og pasienter med sterkt redusert lungekapasitet. Disse bør som hovedregel planlegges innlagt, men man kan individuelt vurdere mulighetene for hjemsendelse samme dag.

\section{Informasjon om pasienten}

Selv om relativt få hjemmefungerende, elektive pasienter avvises for dagkirurgi på grunn av dårlig generell helse, er det viktig at anestesipersonalet vet mest mulig om pasientens helse og funksjonsnivå for å planlegge et optimalt forløp $(3,8,12)$.

Som et utgangspunkt gjelder det at anestesøren er interessert $i$ alt som er registrert av avvik fra fullgod helse og funksjon i en komplett sykehusjournal med full anamnese, status og tilleggsundersøkelser. Dette kan meget vel være en mest mulig komplett utskrift av primærlegens opplysninger og relevante epikriser som sendes sammen med henvisning til kirurgi, tidligst mulig i prosessen, oftest supplert med et helseskjema som pasienten selv fyller ut i forkant av inngrepet (ramme 3). Noen punkter skal omtales mer i detalj:

- Det er viktig å vite om pasienten har fysiologiske reserver til å klare to trapper i vanlig tempo og om pasienten fungerer normalt hjemme og $\mathrm{i}$ en arbeidssituasjon. I tilfelle nei, stoppes han av tung pust, brystsmerter, muskel-/skjelettplager eller annet? Hjertesvikt utgjør en særlig risikofaktor ved anestesi.

- Opplysninger om pasientens tidligere sykdommer er viktig, spesielt alt som er knyttet til hjerte-kar og lunge-luftveier. Ved ev. forekomst av angina pectoris er det viktig å angi grad og om tilstanden er stabil.

- Spesielle erfaringer fra tidligere narkoser bør nevnes.

- En liste over pasientens medikamentforbruk og eventuelle allergier skal foreligge. Spesielle tiltak må gjøres dersom pasienter bruker antikoagulerende midler eller behandles medikamentelt for diabetes. Indikasjonen for bruk av antikoagulerende midler og platehemmere bør angis. Det viktige er at opplysninger om sykdom og medisinering kommer frem;

\section{Ramme 1}

\section{Utskrivingskriterier til hjem/} sykehotell etter dagkirurgi

Bearbeidet etter metodebok ved Oslo universitetssykehus, Ullevål (9)

Pasienten skal:

- Være våken, klar og orientert - dvs med forbehold om stabilt redusert preoperativ tilstand

- Ha stabil sirkulasjon og respirasjon

- Kunne kle på seg med litt hjelp, være mobiliserbar til å sitte i bil

- Ikke ha noen kirurgiske problemer eller kjente komplikasjoner som krever fagoppfølging

- Ha evne til å drikke

- Ha evne til å late vannet - kan utelates, hvis man informerer godt om at dette må fungere innen natten

- Ikke ha kvalme og ha lite/ingen smerte: må kunne forventes godt kontrollert uten intravenøse injeksjoner

- Ha reiseavstand og reisetid hjem innenfor det som er akseptabelt for pasienten og sikkert håndterbart innenfor en «verst tenkelig tilfelle»-tenking med henblikk på mulige komplikasjoner og problemer. I en del tilfeller kan sykehotell eller hotell være et aktuelt alternativ

- Ha ansvarlig ledsager hos seg til neste dag - kan fravikes ved mindre inngrep i lokalanestesi eller ved overnatting i pasienthotell med oppfølging på rommet

\section{Ramme 2}

\section{Kortversjon av ASA-klassifikasjonen}

Det vises til Fasting (10) for utfyllende versjon

Denne skal angi pasientens generelle helse umiddelbart før oppstart av det aktuelle inngrep:

- ASA 1 Helt frisk pasient lingen heftelser ved helsen)

ASA 2 Stort sett frisk pasient (heftelser ved helsen, men normal funksjon)

ASA 3 Klinisk syk pasient. lalvorlig syk, lett/moderat funksjonsbegrensingl

ASA 4 Svært syk pasient. lalvorlig syk, alvorlig funksjonsbegrensing)

ASA 5 Moribund pasient (stor risiko for snarlig død)

kirurg eller anestesiansvarlig vil deretter lage et individuelt opplegg forut for operasjonen.

- Etter øvre luftveisinfeksjoner er luftveiene irritable i 1-2 uker, slik at generell anestesi om mulig bør utsettes, men spe- 


\section{Ramme 3}

Momenter som bør kartlegges og besvares av fastlegen/indikasjonsstillende kirurg før anestesi iverksettes (nei, ja eller ja med utfyllende kommentarer). Noen av punktene kan besvares av pasienten $\mathrm{i}$ form av egenskjema som sendes til den dagkirurgiske enheten Punktene kan brukes som mal til egenskjema for pasienten og/eller sjekkliste for henvisende lege. Bearbeidet etter metodebok ved Oslo universitetssykehus, Ullevål (9)

Helse og sykdom

- Høyt blodtrykk, hjertesykdom eller blodpropp, brystsmerter, uregelmessig puls eller hovne bein. Grad av symptomer og status: Stabil?

- Astma, kols eller annen lungesykdom? (NB Hvis ja, ta med alle medisiner operasjonsdagen!) Grad av symptomer og status: Stabil?

- Diabetes eller stoffskiftesykdom? (NB Hvis diabetes, ta med medisiner og måleutstyr!) Grad av symptomer og status: Stabil?

- Gjentatte infeksjoner eller smittsom sykdom, for eksempel hepatitt/gulsott eller hiv

- Magesår, magekatarr, spiserørsbrokk eller sure oppstøt

- Luftveishinder, som alvorlig snorkesyke (søvnapné, bruk av kontinuerlig luftveisovertrykk - CPAP)

- Tendens til å blø rikelig, få blåmerker eller betennelse i sår

- Tidligere blodpropp i lunger, dyp venetrombose eller påvist genetisk økt koagulasjonstendens

- Epilepsi, migrene, hjerneslag/drypp, muskelsvinn/lammelse eller annen lidelse i nervesystemet

- Kreftsykdom

- Leddgikt eller andre alvorlige skjelett- og muskelplager

- Allergi mot medisiner, lateks, matvarer, pollen eller annet

- Opphopning av spesielle sykdommer i familien?

- Innlagt i sykehus i utlandet innenfor de seneste seks måneder eller fått påvist meticillinresistente gule stafylokokker - MRSA (særlig motstandsdyktig bakterie)

Medikamenter

- Hvilke medisiner bruker pasienten?

- Medisiner som pasienten ikke tåler. Hvilken reaksjon hadde pasienten?

- Bruker pasienten blodfortynnende medisiner? Hvis ja: Hvilke?

Bedøvelse og operasjon

- Har pasienten fått narkose tidligere?

- Har det vært problemer med tidligere narkose eller bedøvelse?

- Er det opplysninger om alvorlige problemer med bedøvelse eller operasjon i pasientens nære slekt?

- Har pasienten hatt mye kvalme eller oppkast etter tidligere operasjoner eller narkose?

Andre spørsmål

- Har pasienten tannprotese, implantater eller løse tenner?

- Har pasienten problemer med å gape høyt eller bøye nakken?

- Røyker pasienten? Hvor mye?

- Har pasienten (eller har pasienten hatt) et alkohol- eller tablett-/narkotikamisbruksproblem?

- Har pasienten noen særlige behov/ønsker i forbindelse med operasjon eller anestesi?

- Har pasienten noen som kan være hjemme hos seg til dagen etter operasjonen?

- Pårørende som kan kontaktes operasjonsdagen: Tlf:

Viktige punkter fra somatisk status

- Pasientens høyde og vekt

- Tegn til infeksjoner, pågående sykdommer

- Pasientens blodtrykk og hjertefrekvens (regelmessig?]

- Funn ved undersøkelse av hjerte og lunger

- Funksjonsinnskrenkning (klarer pasienten å gå to trapper uten pause?)

Ledsagende dokumentasjon

- Utskrift av epikriser, spesialistvurderinger

- Utskrift av røntgen- og laboratoriefunn

- Ev. EKG

sielt for barn med øre-nese-hals- problemer kan dette kravet være vanskelig å innfri. I praksis er det slik at man vil akseptere å anestesere et barn med lett øvre luftveisinfeksjon, dvs. at det ikke skal være tegn på bakteriell infeksjon, feber, forhøyet CRP eller tydelig affisert allmennfunksjon.
- I utgangspunktet skal planlagt kirurgi gjøres i faser uten interkurrente sykdommer. Hos kronisk syke kan dette av og til være vanskelig, og det er da viktig å få opplysninger om pågående infeksjoner, diaré, oppkast og/eller underernæring.

- Røyke- og alkoholvaner og jevnlig analgetikabruk kan ha betydning for anestesidoseringen, likeledes er det viktig å få frem misbruksproblematikk, ustabil sosial situasjon og ev. fare for blodsmitte (hiv eller hepatitt).

Skjemaet i ramme 3 kan virke detaljert og er ment som en huskeliste for å få frem helseanmerkninger. Hos en helt frisk pasient kan skjemaet godt summeres opp i en enkelt setning som: «Pasienten er for øvrig frisk, bruker ingen medikamenter og har ingen kjente allergier.»

\section{Informasjon til pasienten}

Pasienten må sørge for å ha en ledsager til å være hos seg frem til neste dag. Hvis det er vanskelig for ledsager å hente pasienten, kan drosjesjåfør oftest fungere som ledsager på hjemveien. Hvis det er lang reise hjem eller hvis andre forhold tilsier det, er det mange steder mulig å få til overnatting med ledsager på sykehotell etter inngrepet. Pasienten må være forberedt på at han ikke kan kjøre bil før neste dag, at man ikke bør ha krevende oppgaver eller viktige beslutninger foran seg etter hjemkomst på operasjonsdagen, og at man bør avstå fra å nyte alkohol samme dag.

\section{Mat og drikke}

Pasienten skal møte fastende, dvs. ikke ha spist de siste seks timene før inngrepet og ikke ha drukket de siste to timene. Melk og melkeprodukter regnes som mat i denne sammenheng, unntatt morsmelk som kan gis inntil tre timer før anestesistart. Med drikke menes klare væsker, slik som vann, kaffe, te, saft, brus etc. Unntak fra totimersregelen er svelging av medisiner i et par slurker vann, som kan gjøres inntil en time før planlagt start av anestesi (13).

\section{Annet}

Pasienten skal ikke røyke på operasjonsdagen, det ideelle er selvfølgelig om man kan få overtalt pasienten til å slutte å røyke 4-6 uker før inngrepet. Røykestopp gir økt luftveisirritabilitet i noen uker etterpå, og pasienten bør helst være gjennom denne fasen før et planlagt inngrep utføres. Pasienten skal møte usminket og uten neglelakk, dette fordi man under anestesi er interessert $i$ å observere farge på hud og negleseng som kliniske parametere. Tannprotese kan beholdes på. Mange pasienter opplever sterkt ubehag når denne tas ut før de er på operasjonsstuen.

\section{Faste medisiner}

Som hovedregel skal pasienten ta sine vanlige medisiner, inkludert morgenmedisiner på operasjonsdagen, akkurat slik de pleier. Vik- 
tige unntak er antidiabetika og alle medikamenter som gir økt blødningsfare (f.eks. warfarin, acetylsalisylsyre og andre platehemmere samt tradisjonelle NSAID-preparater).

En hovedregel for diabetikere er at de følger sine vanlige rutiner for kost og antidiabetika (herunder insulin) frem til midnatt før operasjonsdagen. Operasjonsdagen skal de verken ta antidiabetika, spise eller innta sukkerholdig drikke før de møter opp på dagkirurgienheten. Her vil man sjekke aktuelt blodsukker og lage et individuelt opplegg videre.

Ved bruk av warfarin eller platehemmere må det avtales individuelt opplegg for eventuell pause $\mathrm{i}$ behandlingen preoperativt avhengig av indikasjon veid mot blødningsfare ved planlagt inngrep. Hos pasienter med innsatt koronar stent eller mekanisk hjerteklaff bør pause i pågående behandling med acetylsalisylsyre, antikoagulantia (warfarin) og potente platehemmere bare skje på spesiell indikasjon (14).

Lavdosert østrogenbehandling for menopauseplager behøver ikke seponeres. Østrogenholdige p-piller bør om mulig seponeres to til fire uker forut for inngrepet pga. trombosefare, men dette kravet er ikke absolutt fordi moderne p-piller inneholder lite østrogen. P-piller kan brukes som normalt hvis pasienten for øvrig er normalvektig, ikkerøykende, uten egen eller familiær anamnese med tanke på trombosetendens og det forventes raskt mobilisering etter inngrepet.

Hvis pasienten er vant til å bruke sovemedisin eller beroligende medisin, kan slike godt benyttes i vanlig dose forut for inngrepet, men det er viktig at anestesøren får beskjed om dette, slik at ev. justering av anestesidoser kan foretas.

Anbefalinger vedrørende eventuell pause før operasjonsdagen med renin-angiotensinblokkerende preparater (ACE-hemmere og AT-II-antagonister) varierer. Pasienter kan være hemodynamisk mer ustabile med disse medikamentene under epidural eller spinal anestesi og generelt ved inngrep med noe blodtap. En tilnærming er å opprettholde denne typen medikamenter hos hjertesviktpasienter, mens de som får høyere doser for sin hypertoni, bør seponere morgendosen forut for inngrepet (15).

\section{Komplikasjoner \\ og plager postoperativ}

Søvn

Hvis pasienten har fått generell anestesi eller intravenøs sedasjon, er noe tretthet og slapphet vanlig ut operasjonsdagen. Man får også ødelagt søvnrytmen ved å ligge lenge i narkose, og etterslep av opioider kan gi redusert søvnkvalitet. Pasienter kan således de første nettene og dagene etter operasjonen oppleve både redusert og økt søvnmengde, av og til med noe uro og kraftige drømmer.

\section{Kognitiv funksjon}

Hos enkelte pasienter, hyppigere hos eldre, kan den intellektuelle kapasiteten være mid- lertidig noe redusert i uker, opptil måneder etter et inngrep (16). Dette er vanligvis ikke uttalt og oftest bare diagnostiserbart hvis man gjør spesielle tester.

\section{Smerte}

Det skal være et behandlingsmål at den postoperative smerteintensiteten ikke skal overskride 3 på en skala $0-10$, der 10 er verst tenkelige smerte. Pasienten bør før avreise ha fått et godt analgetisk grunnlag med lokalanestesi og ikke-opioide midler, ev. med et lite tillegg av opioid $(17,18)$. Etter hjemkomst er det viktig at pasienten tar forebyggende basismedikasjon bestående av paracetamol og oftest et NSAID-preparat de første dagene etter inngrepet (ramme 4). Ved behov for analgesi utover dette, kan oksykodon eller andre opioide depottabletter vurderes i 1-3 dager ved forventet sterk, jevn smerte, mens oksykodon vanlige tabletter kan brukes ved sterk gjennombruddssmerte. Kodeinholdige preparater kan vurderes, men virker ikke hos alle pasienter på grunn av genetisk betingede enzymvariasjoner. Tramadol kan være et alternativ, likeså buprenorfin som er en partiell opioidagonist med noe svakere maksimal effekt enn andre opioider.

\section{Kvalme}

Forekomsten av kvalme har gått betydelig ned de senere årene pga. mindre emetogene anestesimidler og god profylakse før utskrivning fra dagkirurgienheten (19). Hos pasienter som blir kvalme etter hjemsendelse, er det viktig å utelukke spesifikke årsaker, som bruk av opioider, for rask mobilisering og bevegelse, lavt blodtrykk, dehydrering, hypoksi eller kirurgiske komplikasjoner. Det er således viktig å unngå brå bevegelser, prøve å ta til seg væske $\mathrm{i}$ små, hyppige mengder og unngå opioide analgetika hvis de ikke er nødvendige. Forskjellige antiemetika i form av tabletter, stikkpiller eller sugetabletter kan prøves (ramme 4), eksempelvis metoklopramid, haloperidol, serotoninantagonister (ondansetron) ev. glukokortikoider ved langvarige plager (19).

\section{Sårstell}

Mange pasienter er opptatt av sårstell og siving fra såret ut $\mathrm{i}$ bandasjen. Det er normalt med litt siving fra såret det første døgnet, eventuelt såpass at bandasje bør skiftes. Avhengig av sårtype så kan det være aktuelt med kompresser og ev. kompresjon, andre ganger kan vanlig sterilt plaster være tilstrekkelig. Ved en del inngrep vil subkutane hematomer kunne sprenge noe initialt og senere gi misfarging av huden som kan vedvare i mange uker. Hvorvidt det er brukt resorberbare sting eller sting som skal fjernes etter 5-12 dager (avhengig av operasjonstype) vil variere. Pasienten må få tydelig instruksjon om hva som gjelder.

\section{Infeksjoner}

Infeksjoner er relativt uvanlig etter dagkirurgi, men eventuell feberstigning, rubor og

\section{Ramme 4}

Profylakse og behandling av smerte og kvalme etter utskrivning fra dagkirurgi. Bearbeidet etter metodebok ved Oslo universitetssykehus, Ullevål (9)

Basismedikasjon (skal tas fast profylaktisk)

a) Paracetamol $1 \mathrm{~g} \times 4$ (voksne) så lenge det er behov for analgetika

og

b1) NSAID-preparat (f.eks. ibuprofen, naproksen, diklofenak) i 1-5 døgn, avhengig av behov

eller

b2) COX-2-selektivt NSAID-preparat (f.eks.celecoxib, etoricoxib) erstatter NSAID-midler hos pasienter med spesiell indikasjon

Ved tilleggsmerte (gis i tillegg til basis)

a) Kortvarig behov: oksykodon tablett, minst 1 time mellom hver dosering

b) Konstant ekstra behov: oksykodon depottablett, $2 \times$ daglig

Alternativ til oksykodon ved tilleggsmerte

a) Bytte ut deler av paracetamoldosen i basismedikasjon med paracetamol + kodein $(500+30 \mathrm{mg}), 1-2$ tabletter, inntil $4 \times$ daglig.

b) (respektere maksimal døgndose for paracetamoll

c) Gi tramadol i tillegg til basis

d) Gi buprenorfin i tillegg til basis

Ved kvalme eller oppkast hjemme Hvis ikke ett medikament hjelper, kombineres to eller tre.

- Ondansetron smeltetablett

eller

- Metoklopramid stikkpille (ev. tablett) eller

- Nevroleptikum tabletter (lavdose haloperidol, perfenazin eller proklorperazin]

hevelse i sårområdet 2 -4 dager etter inngrepet bør vekke mistanke (20). Det er meget viktig å fange opp tidlige symptomer på bukhinnebetennelse etter kirurgi hvor man har vært inne i eller i nærheten av bukhulen (f.eks. gastrokirurgi, gynekologiske inngrep og brokkirurgi).

\section{Sjeldnere komplikasjoner}

Mer sjeldne komplikasjoner kan forekomme etter spesielle typer regionalanestesi: hodepine etter epidural- eller spinalanestesi, pneumothorax etter lokalbedøvelse under kraveben eller på hals og forbigående prikking og nummenhet i 1-2 dager i områder som har vært utsatt for lokal eller regional bedøvelse (21).

\section{Oppfølging}

Det er legitimt både for pasienten og for dem som henviser pasienten til dagkirurgisk behandling å forvente god service og kom- 
munikasjon tilbake fra behandlende enhet (e-ramme 5)

For de fleste dagkirurgiske inngrep er det ikke vanlig å avtale poliklinisk etterkontroll ved enheten eller hos operatøren. Derimot er det viktig at pasienten får med seg grundig skriftlig og muntlig informasjon om inngrepet ved avreise, herunder epikrise. Pasienten skal ha klar beskjed om hvor de kan ringe hvis de har spørsmål eller lurer på om komplikasjoner er oppstått. De fleste dagkirurgiske enheter praktiserer også å ringe pasientene rutinemessig første hverdag etterpå for å sikre seg at forløpet er tilfredsstillende. En del sender også ut ferdig frankerte spørreskjema for kvalitetssikring.

For øvrig er det tanken at primærhelsetjenesten skal være pasientens naturlige kontakt utover det rent postoperative i forløpet etter et dagkirurgisk inngrep. Pasient og eventuelt primærhelsetjenesten skal sikres lav terskel for å kunne ta kontakt med enheten eller vakthavende på modersykehuset på døgnbasis.

Tilbakemelding til de dagkirurgiske avdelinger om avvik eller uønskede hendelser som f.eks. postoperativ infeksjon, venetrombose, lungeemboli, funksjonssvikt etc. er også viktig for stadig å øke kvaliteten på behandlingen $(11,22)$.
Oppgitte interessekonflikter: Ingen

e-ramme 5 finnes i artikkelen på

www.tidsskriftet.no

Litteratur

1. Ræder J. Omfang av dagkirurgi. Tidsskr Nor Lægeforen 1996; 116: 372-6.

2. Sintef. SAMDATA. Nøkkeltall for spesialisthelsetjenesten 2007. www.sintef.no/Projectweb/ Startsiden/SAMDATA-pa-nett (28.9.2009).

3. Ræder J. Dagkirurgi - anestesiologiske aspekter Tidsskr Nor Lægeforen 1990; 110: 977-80.

4. Lemos P. Day Surgery. Development and practice. Porto: IAAS, 2006

5. Engbaek J, Bartholdy J, Hjortso NC. Return hos pital visits and morbidity within 60 days after day surgery: a retrospective study of 18,736 day surgical procedures. Acta Anaesthesiol Scand 2006 . 50: $911-9$.

6. Vila H, Soto R, Canror AB et al. Comparative outcomes analysis of procedures performed in physician offices and ambulatory surgery centers. Arch Surg 2003; 138: $991-5$.

7. Aasbo V, Thuen A, Raeder J. Improved long-lasting postoperative analgesia, recovery function and patient satisfaction after inguinal hernia repair with inguinal field block compared with general anesthesia. Acta Anaesthesiol Scand 2002; 46 : $674-8$

8. Kvalsvik O. Pasientutvelgelse for dagkirurgi. Tidsskr Nor Lægeforen 1996; 116: 500-3.

9. Ullevål universitetssykehus. Dagkirurgi. www.ulleval.no/modules/module_123/ proxy. asp?ilnfold $=20784 \&$ iCategoryld $=901 \&$ DisplayType $=2$ (28.9.2009)

10. Fasting S. Risiko ved anestesi. Tidsskr Nor Legeforen 2010; 130: 498-502.
11. Shnaider I, Chung F. Outcomes in day surgery. Curr Opin Anaesthesiol 2006; 19: 622-9.

12. Ræder J. Dagkirurgi - preoperative undersøkelser. Tidsskr Nor Lægeforen 1996; 116: 497-9.

13. Soreide E, Eriksson LI, Hirlekar G et al. Pre-operative fasting guidelines: an update. Acta Anaesthesiol Scand 2005; 49: 1041-7.

14. Chassot PG, Delabays A, Spahn DR. Perioperative antiplatelet therapy. Br J Anaesth 2007; 99: 316-28.

15. Licker M, Morel D, Denis R. Inhibitors of the renin angiotenin system: implications for the anaesthesiologist. Curr Opin Anaesth 1998; 11: 321-6.

16. Canet J, Raeder J, Rasmussen LS et al. Cognitive dysfunction after minor surgery in the elderly. Acta Anaesthesiol Scand 2003; 47: 1204-10.

17. Dahl V, Ræder J. Non-opioid postoperative analgesia. Acta Anaesthesiol Scand 2000: 44: 1191-203.

18. Hval K, Thagaard KS, Schlichting E et al. The prolonged postoperative analgesic effect when dexamethasone is added to a nonsteroidal antiinflammatory drug (rofecoxib) before breast surgery. Anesth Analg 2007: 105: 481-6.

19. Ræder J. Postoperativ kvalme og oppkast. Tidsskr Nor Lægeforen 2005; 125: $1831-2$.

20. Grogaard B, Kimsas E, Raeder J. Wound infection in day-surgery. Ambul Surg 2001; 9: 109-12.

21. Dahl V, Raeder J. Regional anaesthesia in ambulatory surgery. Curr Opin Anaesthesiol 2003; 16: 471-6.

22. Grøgaard B, Aasbø V, Ræder J. Innleggelse og re-innleggelse fra en dagkirurgisk enhet. Erfaring etter 2411 pasienter. Tidsskr Nor Lægeforen 1996 ; 116: $742-5$.

Manuskriptet ble mottatt 5.10. 2008 og godkjent

11.10. 2009. Medisinsk redaktør Siri Lunde. 